\title{
Does density-induced stress promote density-dependent reproduction in root voles? Two field experiments
}

\author{
guo-zhen shang ${ }^{1}$, Shouyang $\mathrm{Du}^{2}$, Yanbin yang ${ }^{3}$, Yan $\mathrm{Wu}^{4}$, Yi-Fan $\mathrm{Cao}^{1}$, and Jianghui Bian ${ }^{1}$ \\ ${ }^{1}$ Northwest Institute of Plateau Biology, Chinese Academy of Sciences \\ ${ }^{2}$ College of Animal Science and Veterinary Medicine, Henan Institute of Science and \\ Technology \\ ${ }^{3}$ College of Veterinary Medicine, Henan Agricultural University \\ ${ }^{4}$ Hangzhou Normal University
}

July 27,2021

\begin{abstract}
Density dependence in reproduction plays an important role in stabilising population dynamics via immediate negative feedback from population density to reproductive output. Although previous studies have shown that density dependence is associated with strong spacing behaviour and social interaction between individuals, the proximal mechanism for generating densitydependent reproduction remains unclear. In this study, we investigated the effects of density-induced stress on reproduction in root voles. Founder population enclosures were established by introducing six (low density) and 30 (high density) adults per sex into per enclosure (four enclosures per density in total) during the breeding season from April to July 2012 and from May to August 2015. Faecal corticosterone metabolite (FCM) levels, reproductive traits (recruitment and the proportion of reproductive condition), and founder population numbers were measured following repeated live-trapping in both years. The number of founders was negatively associated with recruitment rates and the proportion of reproductive conditions, displaying a density-dependent reproduction. FCM level was positively associated with the number of founders. The number of founder females indirectly affected the proportion of reproductive females in 2012 and recruitment in 2015 through their FCM levels; the effect of the number of male founders on the proportion of reproductive condition was mediated by their FCM level in 2012 , but the effect was not found in 2015. Our results showed that density-induced stress affected density-dependent reproduction and that density-induced stress is one ecological factor generating density-dependent reproduction.
\end{abstract}

\section{Does density-induced stress promote density-dependent reproduction in root voles? Two field experiments}

Guozhen Shang, ${ }^{1,}$,\#, Shouyang $\mathrm{Du}^{3,}$, Yanbin Yang, \#, Yan $\mathrm{Wu}^{5}$, Yifan $\mathrm{Cao}^{1,2}$, Jianghui Bian ${ }^{1,2}$

${ }^{1}$ Key Laboratory of Adaptation and Evolution of Plateau Biota, Northwest Institute of Plateau Biology, Chinese Academy of Sciences, Xining 810001, China

${ }^{2}$ Qinghai Key Laboratory of Animal Ecological Genomics, Xining,810001, China

${ }^{3}$ College of Animal Science and Veterinary Medicine, Henan Institute of Science and Technology, Xinxiang 453003, China

${ }^{4}$ College of Veterinary Medicine, Henan Agricultural University, Zhengzhou 450002, Henan 45000, China

${ }^{5}$ School of Life and Environment Sciences, Hangzhou Normal University, Hangzhou 310012, China.

\# These authors contributed equally to this paper. 
Running Head: Density dependence and density stress

Correspondence authors: Jianghui Bian, Email: bjh@nwipb.cas.cn; Yan Wu, Email: wuyanqh@163.com.

Abstract: Density dependence in reproduction plays an important role in stabilising population dynamics via immediate negative feedback from population density to reproductive output. Although previous studies have shown that density dependence is associated with strong spacing behaviour and social interaction between individuals, the proximal mechanism for generating density-dependent reproduction remains unclear. In this study, we investigated the effects of density-induced stress on reproduction in root voles. Founder population enclosures were established by introducing six (low density) and 30 (high density) adults per sex into per enclosure (four enclosures per density in total) during the breeding season from April to July 2012 and from May to August 2015. Faecal corticosterone metabolite (FCM) levels, reproductive traits (recruitment and the proportion of reproductive condition), and founder population numbers were measured following repeated live-trapping in both years. The number of founders was negatively associated with recruitment rates and the proportion of reproductive conditions, displaying a density-dependent reproduction. FCM level was positively associated with the number of founders. The number of founder females indirectly affected the proportion of reproductive females in 2012 and recruitment in 2015 through their FCM levels; the effect of the number of male founders on the proportion of reproductive condition was mediated by their FCM level in 2012, but the effect was not found in 2015. Our results showed that density-induced stress affected density-dependent reproduction and that density-induced stress is one ecological factor generating density-dependent reproduction.

Keywords: density-dependence, density, stress, FCM level, reproduction, root vole

\section{Introduction}

Small mammals in the Northern Hemisphere often have a broad spectrum of population dynamics and seasonal fluctuations. Any pattern of population dynamics is caused by changes in demographic parameters (Inchausti et al., 2009). Thus, knowledge regarding the factors influencing demographic parameters is of great importance for understanding population dynamics.

In iteroparities such as microtine rodents, density dependence in reproduction plays an important role in stabilising population dynamics via immediate negative feedback from population density to reproductive output (Ostfeld et al., 1993). Although research regarding density dependence has often been criticised (Krebs, 2002), density-dependent reproduction does occur in seasonal territorial microtine rodents with strong social effects on demographic parameters during breeding season, such as the grey-sided vole (Clethrionomys rufocanus ) (Saitoh, 1981), meadow vole (Microtus pennsylvanicus ) (Ostfeld et al., 1993), water vole (Arvicola terrestris ) (Saucy, 1994), common vole (Microtus arvalis ) (Inchausti et al., 2009) and bank vole (Clethrionomys glareolus ) (Koskela et al., 1999) and Yangtze vole (M. fortis calamorum ) (Zhang et al., 2010). The mechanisms underlying density-dependent reproduction are associated with direct and indirect interactions among individuals, such as consumptive and non-consumptive competition (Rödel et al., 2004), as well as social suppression for juvenile maturation (Saitoh, 1981).

Christian (1971) suggested that density-dependent reproduction might be the result of increased adrenocorticotropic hormone secretion in response to increased density and decreased or suppressed reproduction. However, Christian's research has been criticised because it was largely performed on captive animals in a laboratory setting (Krebs \& Myers, 1974; Lee \& McDonald, 1985); moreover, there has been limited evidence supporting their hypothesis. Nonetheless, studies have shown that factors known to influence density dependence of reproduction, such as social interference and antagonistic interactions, are normally modulators of individual stress responses in the population and act as stressors to activate the hypothalamic-pituitaryadrenal axis and subsequent secretion of glucocorticoids (GC), a critical hormone in stress response (Sheriff et al., 2009). Studies on free-living, non-social, territorial vertebrates demonstrated that population density is usually positively associated with GC levels (see review by Creel et al., 2013, but see Harper \& Austad, 2004; Kuznetsov et al., 2004; Charbonnel et al., 2008). In voles specially, increase in population density was associated with an increase in corticosterone levels (Boonstra \& Boag, 1992; Novikov \& Moshkin, 1998; Bian 
et al., 2015). For some social mammals living in groups, dominant individuals have higher reproductive success and heightened GCs level (see review by Sapolsky, 2005); however, evidence from laboratory studies and free-ranging iteroparous territorial rodents have shown that chronically elevated GC concentrations inhibit the gonadal axis function and lead to a negative effect on reproduction (see review by Creel et al., 2013). Thus, density-dependent reproduction in microtine rodents may be the result of elevated corticosterone concentrations in response to increased density.

In the present study, we investigated the effects of density-induced stress on reproduction via manipulation of the population density in the root vole (Microtus oeconomus ). This is part of a larger multifaceted project examining the effects of density-induced maternal stress on population dynamics. Parental enclosures for breeding offspring were established by introducing six and thirty adults of each sex in low- and high-density enclosures, respectively, in 2012 and 2015. Our previous papers have reported that high parental population density was approximately three times higher compared with low parental population density at the end of the experimental period in 2012 (Bian et al., 2015). Moreover, the population under high-density conditions showed higher mean faecal corticosterone metabolite (FCM) levels than the population under low-density conditions in both 2012 (Bian et al., 2015) and 2015 (Yang et al., 2018). In this study, we present unpublished data from the same parental populations in 2012 and 2015, which include recruitment and proportion of reproductive conditions and the numbers of male and female founders in both years. We separately tested the difference in reproductive traits between high-and low-density parental populations, and analysed how the number of founders and FCM levels affected reproduction by the recursive model in the structural equation model (SEM). We aimed to test the hypothesis that density-dependent reproduction in voles may be due to the suppressive effects of density-induced stress on reproduction. We predicted that a high-density population would have lower recruitment and the proportion of reproductive condition, and the effects of founder number on both reproductive traits would be mediated by FCM levels.

\section{Materials and methods}

\section{Root voles in the study area}

Our study was conducted at Haibei Alpine Meadow Ecosystem Research Station, Menyuan County, approximately $155 \mathrm{~km}$ north of Xining, the capital city of Qinghai province, People's Republic of China ( $37^{\circ} 370^{\prime} \mathrm{N}$, $\left.101^{\circ} 120^{\prime} \mathrm{E}\right)$. The area is a secondary vegetation type meadow with a dense leaf layer. The major plant species include Elymus nutans, Poasp., Kobresia humilis, and Potentila fruticosa. The root vole is the most common rodent in the study area. Root-vole populations in this area fluctuate only seasonally, with the lowest levels occurring in early spring; multiyear cycles are weak or absent (Jiang et al., 1991). Root voles have a preference for dense vegetation (mainlyE. nutan s) (Liu et al., 1991; Bian et al., 1994). The average population size in the habitat ranges from 217 to 280 voles ha $^{-1}$ in autumn (Bian et al., 1994), where grazing activities had a limited population density of approximately 400 voles ha ${ }^{-1}$ in autumn (Sun et al., 2002). The breeding season typically lasts from April to late October. Females have exclusive territoriality during the breeding season; males, conversely, have large area ranges that extensively overlap with those of other males (Sun et al., 1982). The lifetime of free-ranging individuals is $<1$ year. Spring-born individuals attain sexual maturity in the year they are born; fall-born voles remain reproductively inactive during winter (Bian et al., 2015).

\section{Experimental facility}

The experiment was undertaken in eight 0.15 -ha $(50 \times 30 \mathrm{~m})$ outdoor enclosures in 2012 and 2015 . The enclosures were constructed using galvanised steel panels $(1.5 \mathrm{~m}$ aboveground and $0.5 \mathrm{~m}$ belowground), which prevented mammalian predators from gaining entry. Avian predators were excluded by a $3 \times 3 \mathrm{~cm}$ grid wire mesh held aloft by a central pillar $(10 \times 250 \mathrm{~cm})$ in each enclosure. Each enclosure was equipped with 60 laboratory-made wooden traps (Bian et al., 2015), spaced in a $5 \times 5 \mathrm{~m}$ grid. Each trap was covered with a wooden sheet to protect it from exposure to precipitation and temperature extremes.

\section{Establishment of populations and live-trapping}


A total of 288 voles of each sex, 6 months of age or older, were separately used to establish the enclosure populations in 2012 and 2015. They were either F2 generations born in the laboratory or captured as juveniles in the previous year. All individuals were tagged in the ear with identifying metal tags. The populations were introduced into the enclosures in April 2012 and May 2015 at two density conditions. The low-density condition consisted of six adults per sex in each of the four enclosures, and the high-density condition consisted of 30 adults per sex in each of the other four enclosures in 2012 and 2015. A high-density condition $\left(400\right.$ vole $\mathrm{ha}^{-1}$ ) was observed in the habitat with dense vegetation where grazing activities were limited (Sun et al., 2002). The initial body weights did not differ among the voles in the different enclosures $\left(F_{7,280}=\right.$ $1.72, P=0.103$ in 2012, $F_{7,280}=0.192$, and $P=0.987$ in 2015). Live-trapping started after allowing the animals to acclimate to their new environments for two weeks and lasted until late July 2012 and August 2015, respectively. Standard capture-record-recapture methods were used throughout the study. Six trapping sessions were conducted in 2012 and seven in 2015; each consisted of three trapping days. The time interval between any two trapping sessions was one week. The traps were set between 7 AM and 7 PM, baited with a bit of carrot, checked every $2 \mathrm{~h}$, and locked closed when trapping did not occur. Following each capture, we recorded animal identification, sex, and body mass. Females were considered reproductive if they had enlarged nipples and teats barren of hair. Males were considered in breeding conditions if their testes were scrotal rather than abdominal. The animal was, then, released at the point of capture after handling. The F1 offspring born in the enclosures were captured at 20-30 days of age and moved to the laboratory for use in subsequent experiments (Bian et al., 2015; Yang et al., 2018).

\section{Fecal corticosterone metabolite (FCM) measurement}

FCM levels reflect the level of circulating corticosterone that occurred 10-12 h previously in root voles (He et al., 2013), and FCM is derived primarily from plasma-free corticosterone in rodents (Sheriff et al., 2010). Faecal samples for the FCM analysis were collected during the first $2 \mathrm{~h}$ of trapping (09:00-11:00 AM), and each captured animal was collected once within a 3-day trapping session; thus, all animals provided only a single sample in each trapping session. Meanwhile, each trap was cleaned with water before collecting the faecal sample, ensuring that the samples were not influenced by the previous trapping or time of day. Traps used to sample faeces only had a few carrots. Faecal samples from pregnant females were not collected to avoid confounding effects of reproduction states on FCM levels (McDonald, 1998; Edwards \& Boonstra, 2018). The total number of faecal samples was 546 and 832 in 2012 and 2015, respectively, throughout each experiment, and they accounted for $59 \%$ and $67 \%$ of the sum of minimum number known alive in each trapping session throughout the duration of experiments in both years (excluding reproductive females). The collected samples were, then, frozen in ice, transported to the laboratory, and stored in a -20degC freezer until analysis. FCM was measured following the methods outlined by Yang et al. (2018), previously validated for root voles. First, the collected faecal samples were lyophilised (Labconco, Kansas City, MO, USA) for 14-18 $\mathrm{h}$, ground into particles, and homogenised in $0.5 \mathrm{~mL} \mathrm{NaOH}$ solution $(0.04 \mathrm{M})$. The extraction of FCM was performed by adding $5 \mathrm{~mL}$ of $\mathrm{CH}_{2} \mathrm{Cl}_{2}$ to the sample $(0.1 \mathrm{~g}$ ), followed by sonication for $15 \mathrm{~min}$ (Pihl \& Hau, 2003) and centrifugation for $15 \mathrm{~min}$ at $3,000 \mathrm{~g}$. After centrifugation, $1 \mathrm{~mL}$ of the solution was taken from the organic layer, diluted with $3 \mathrm{~mL} \mathrm{CH}_{2} \mathrm{Cl}_{2}$, and then mixed with $4 \mathrm{~mL}$ of a mixed solution of sulfuric acid and ethanol (7:3, v:v). The samples were, then, shaken for 2 min and rested for 30 min before separation of the sulfuric acid layer for fluorescence detection. The fluorescence density in each sample was measured using an RF-540 IPC Fluorometer (Shimadzu, Japan) at excitation and emission wavelengths of 470 and $520 \mathrm{~nm}$, respectively, and the FCM concentration in each sample was calculated based on the fluorescence densities produced by varying concentrations of the standard (Chen et al., 2012).

\section{Statistical analysis}

We used the minimum number known alive (MNKA) method to estimate the population numbers. Because the offspring were brought back to the laboratory, the population number per trapping session was estimated by the sum of the number of founders and offspring that were first captured per trapping session in each enclosure. The recruitment rate was calculated as the proportion of recruits captured at $t$ trapping session to adult females captured at $t+2$ trapping session in each enclosure. The proportion of the reproductive 
condition of each sex was calculated as the proportion of reproductive active voles captured at $t$ trapping session to adults captured at the $t$ trapping session in each sex each enclosure.

Founder population densities (Poisson distribution), proportion of reproductive individuals, and recruitment rates (linear model), were analysed using generalized linear mixed models (GLMMs) in SPSS v.19 (IBM, Armonk, NY, USA) with Log/Logit link functions. Because the population number, recruitment, and proportion of reproductive condition were sampled per trapping session during our experiment, these data were analysed using the repeated measures method in GLMMs. Post hoc comparisons for significant treatment effects were followed the sequential Bonferroni post hoc procedure. Comparisons of the means were considered significant at $P<0.05$. All data are expressed as mean +- standard error.

The relationship between the numbers of female or male founder and corresponding recruitment, and the proportion of reproductive condition were analysed with general least-square regression, using the mean number of female or male founders per enclosure in 2012 or 2015 as independent variable and the corresponding mean value of recruitment, and proportion of reproduction per enclosure as dependent variable.

The recursive model in SEM (IBM, Armonk, NY, USA) was used to explore the pathways of how density, through FCM level of founder voles, affected reproductive traits (recruitment and proportion of reproductive conditions). We first considered a full model that included all possible pathways, and, then, sequentially eliminated non-significant pathways until we attained the final model. We reported path coefficients as standardised effect sizes. This analysis was performed with a longitudinal data set, which included cumulative time of trapping session, founder number, recruitment, proportion of reproductive condition and mean FCM level per trapping session in 2012 and 2015, respectively. Founder number was sqrt-transformed and the proportion was arcsine transformed. We used the $\chi^{2}$ test (if $p>0.05$, then no paths were missing, and the model was a good fit) and root mean square error of approximation (RMSEA) (if $p<0.05$, then no paths were missing, and the model was a very good fit) to evaluate the fit of the model.

\section{Results}

\section{Density and recruitment}

Population numbers in the two treatments increased progressively following the trapping sessions in 2012 and 2015 (Fig. 1A, 1C). We found effects of treatment $\left(F_{1,36}=294.38, P<0.001\right.$ for 2012 and $F_{1,42}$ $=30.41, P<0.001$ for 2015$)$, time $\left(F_{5,36}=128.06, P<0.001\right.$ for 2012 and $F_{6,42}=66.36, P<0.001$ for 2015), and treatment $\times$ time $\left(F_{5,36}=17.16, P<0.001\right.$ for 2012 and $F_{6,42}=9.34, P<0.001$ for 2015). The mean estimated population numbers in the low- and high-density treatments at the end of the experiments were $38.07 \pm 4.67$ and $107.99 \pm 8.73$ in 2012 and $42.76 \pm 7.25$, and $111.86 \pm 18.47$ in 2015, respectively.

Founder numbers in the two treatments decreased progressively following the trapping sessions in both years (Fig. 1B, 1D). For founder numbers in 2012 (Fig. 1B), we found effects of treatment $\left(F_{1,72}=433.37, P<\right.$ $0.001)$, sex $\left(F_{1,72}=94.10, P<0.001\right)$, time $\left(F_{5,72}=11.53, P<0.001\right)$, treatment $\times$ time $\left(F_{5,72}=\right.$ 4.81, $P=0.001)$, and sex $\times$ treatment $\times$ time $\left(F_{5,72}=3.30, P=0.010\right)$; however, no effects were found for sex $\times$ treatment $\left(F_{1,72}=2.40, P=0.126\right)$ or sex $\times$ time $\left(F_{5,72}=0.56, P=0.733\right)$. For founder numbers in 2015 (Fig. 1D), we found effects of treatment $\left(F_{1,84}=1814.78, P<0.001\right)$, sex $\left(F_{1,84}=6.11, P=\right.$ $0.015)$, time $\left(F_{6,84}=18.61, P<0.001\right)$, and treatment $\times \operatorname{sex}\left(F_{1,84}=7.92, P=0.006\right)$; however, no effects were found for treatment $\times$ time $\left(F_{6,84}=0.80, P=0.573\right)$, sex $\times$ time $\left(F_{6,84}=0.14, P=0.990\right)$, or treatment $\times$ sex $\times$ time $\left(F_{6,84}=0.75, P=0.612\right)$. The mean estimated numbers of founder males and females in the low-density treatment during the experiment were $2.50 \pm 0.65$ and $3.00 \pm 1.11$ in $2012,3.75$ \pm 0.88 and $3.75 \pm 0.88$ in 2015 . The mean numbers in the high-density treatments were $5.24 \pm 0.82$ and $14.50 \pm 1.67$ in $2012,15.00 \pm 0.88$ and $12.75 \pm 0.88$ in 2015.

For recruitment in 2012 (Fig. 2A), we verified an effect of treatment $\left(F_{1,24}=10.25, P=0.004\right)$, but no effects on time $\left(F_{3,24}=0.64, P=0.600\right)$ or treatment $\times$ time $\left(F_{3,24}=0.43, P=0.736\right)$. For recruitment in 2015 (Fig. 2B), we found effects of treatment $\left(F_{1,30}=9.22, P=0.005\right)$ and treatment $\times$ time $\left(F_{4,30}\right.$ 
$=4.22, P=0.008)$, but not for time $\left(F_{4,30}=1.38, P=0.264\right)$. Populations in low-density enclosures in 2012 and 2015 had $131 \%$ and $97 \%$ higher recruitment than those in high-density enclosures, respectively.

For the proportion of reproductive females and males in 2012 (Fig. 2C, 2E), we found effects of treatment $\left(F_{1,36}=7.72, P=0.009\right.$ for females and $F_{1,35}=7.52, P=0.010$ for males $)$ and time $\left(F_{5,36}=5.42, P\right.$ $=0.001$ for females and $F_{1,35}=434.54, P<0.001$ for males), and marginal interaction between treatment and time $\left(F_{5,36}=2.45, P=0.052\right)$ for females, but not for males $\left(F_{5,35}=0.87, P=0.515\right)$. For 2015 (Fig. 2D, 2F), we verified effects of treatment $\left(F_{1,42}=10.25, P=0.003\right.$ for females, $F_{1,42}=25.60, P<$ 0.001 for males $)$ and time for males $\left(F_{6,42}=11.70, P<0.001\right)$, but not for females $\left(F_{6,42}=0.73, P\right.$ $=0.627)$. Interactions between treatment and time were not found $\left(F_{6,42}=0.54, P=0.773\right.$ for females and $F_{6,42}=0.67, P=0.677$ for males). Populations in low-density enclosures in 2012 and 2015 had $70 \%$ and $107 \%$ higher proportions of reproductive females and $38 \%$ and $69 \%$ higher proportions of reproductive males than populations in high-density enclosures, respectively.

\section{Density-dependent reproduction}

The number of female founders was negatively correlated with mean recruitment $\left(\mathrm{R}^{2}=0.86, \mathrm{y}\right.$ recruitment $=$ $2.39-0.063 \mathrm{x}_{\text {number }}, F_{1,6}=16.51, P=0.007$ for $2012 ; \mathrm{R}^{2}=0.85, \mathrm{y}_{\text {recruitment }}=1.43-0.041 \mathrm{x}_{\text {number }}, F$ ${ }_{1,6}=15.93, P=0.007$ for 2015 ; Fig. $\left.3 \mathrm{~A}\right)$ and with the proportion of reproductive females $\left(\mathrm{R}^{2}=0.97, \mathrm{y}\right.$ proportion $=4.23-0.008 \mathrm{x}$ number, $F_{1,6}=90.42, P<0.001$ for $2012 ; \mathrm{R}^{2}=0.72, \mathrm{y}_{\text {proportion }}=0.72-0.021 \mathrm{x}$ number $F_{1,6}=6.34, P=0.045$ for 2015; Fig. 3B) for both years. Male-founder numbers were negatively correlated with the proportion of reproductive males in $2015\left(\mathrm{R}^{2}=0.90, \mathrm{y}_{\text {proportion }}=0.78-0.015 \mathrm{x}_{\text {number }}, F\right.$ ${ }_{1,6}=24.28, P=0.003$; Fig. 3C), but not in $2012\left(F_{1,6}=2.93, P=0.138\right)$.

\section{Direct and indirect effects of density on FCM level and reproductive traits}

SEM showed that the number of female or male founders had positive association with FCM level in both years (Fig. 4). The number of female founder number indirectly affected the proportion of reproductive females in 2012 (Fig. 4A) and recruitment in 2015 (Fig. 4B) through FCM level, and directly affected the recruitment in 2012 and proportion in 2015. For males (Fig. 4C), the effect of the number of male founders on the proportion of reproductive males was mediated by FCM level in 2012, and the number of males directly affected the proportion in 2015.

\section{Discussion}

In the present study, high-density populations had lower recruitment and proportion of reproductive conditions than low-density populations, and the number of founders was negatively associated with recruitment rates and the proportion of reproductive voles. Because offspring born in enclosures were moved to the laboratory to use to examine the effects of density-induced maternal stress on offspring phenotype (Bian et al., 2015; Yang et al., 2018), the negative relationship between founder numbers and reproductive traits was only due to the suppressive effects of founder numbers on reproduction. In addition, because the enclosures were isolated from common vole predators, predator-induced density dependence on demographic processes was excluded from our study. Therefore, our results concluded that high-density can induce the effect of density dependent reproduction, which corroborates other studies on vole populations as described in the introduction section, indicating a universal of density-dependent reproduction in the population of microtine rodents.

In our previous papers we have reported that high-density population in both years had higher FCM level than low-density population (Bian et al., 2015; Yang et al., 2018). In the present study, we also revealed that FCM levels were positively associated with founder numbers, which also corroborates recent studies on other mammalian species (Boonstra \& Boag, 1992; Novikov \& Moshkin, 1998; Viblanc et al., 2014). However, Harper and Austad (2004) and Charbonnel et al. (2008) did not find a positive correlation between density and FCM levels in water voles and red-backed voles (Clethrionomys gapperi ). In those studies, the faeces were sampled in both breeding and non-breeding season (Harper \& Austad, 2004; Charbonnel et al., 2008) and some samples were from individuals of different ages and reproduction conditions (Harper \& 
Austad, 2004). However, our experiment was performed during the breeding season and the faecal samples of pregnant individuals were not collected, due to pregnancy naturally raising glucocorticoid levels in most mammals, not necessarily as a result of stress but for developmental and energetic reasons (Boonstra \& Boag, 1992; Edwards \& Boonstra, 2018; Edwards et al., 2019). In addition, our previous study has validated the effectiveness of detecting corticosterone levels in the faeces of root voles (He et al., 2013). Therefore, our experiment excluded the confounding effects of reproductive condition, seasonality, and the effects of trapping/handling stress on FCM levels and the differential between our and those results may be due to these confounding factors.

In addition, for unknown reasons, when founder voles were introduced into enclosures to establish an enclosed population, a few voles died during the two-week period of acclimation to their new environments. At the first trapping session in 2012 and 2015, the mean number of founders in high-density treatments was 54.5 and 53.8 voles per enclosure (363 and 358 vole ha ${ }^{-1}$ ), respectively. In this study area, Sun et al. (2002) reported that population density of root vole was 356 vole ha $^{-1}$ in October in the habitat with mainly $E$. nutan $\mathrm{s}$ where grazing activities were limited. Moreover, Rodd and Boonstra (1984) reported that the high density of meadow voles (M. pennsylvanicus ) population in abandoned farmland reached 469 vole ha ${ }^{-1}$ in October. Although we realise that the high-density treatments $\left(400\right.$ vole ha $\left.{ }^{-1}\right)$ were the approximate peak density of natural vole populations in this study area, it is not an unseen natural extreme level. Thus, our findings of correlation between FCM levels and density can represent what happens in a natural vole population.

In semelparous and partially semelparous species (i.e., Australian semelparous marsupial, the arctic ground squirrel Spermophilus parryii plesius ) and dominant individuals in social species and cooperative breeders (i.e., the African wild dog Lycaon pictus, dwarf mongoose Helogale parvula, and grey wolf Canis lupus ), dominance was strongly correlated with reproductive success. However, dominance was also associated with heightened glucocorticoid levels, which reflected either a classical trade-off of reproductive success for potential survival during short mating periods ( $2-3$ weeks), only one breeding period followed by programmed death (see review by Boonstra, 2005), or an adaptive stress response for competing intensely for access to females and maintaining dominant status by frequent physical aggression and challenges (see review by Sapolsky, 2005). Conversely, iteroparous voles breed continuously throughout the breeding season, and antagonistic interaction is not particularly severe. For example, breeding male meadow voles do not appear to be engaging in costly aggressive acts to assert dominance or access females (Edwards et al., 2019). Dominant status is maintained by cues rather than physical combat; subordinates tend to have the highest indices of stress. Thus, for these iteroparous species, elevated corticosterone induced by high population density can suppress reproduction (Wingfield \& Sapolsky, 2003; Boonstra, 2005). In fact, antagonistic behaviour is not the only factor that induces stress responses; increased population or breeding density can also lead to an increase in parasite load, attraction of predators, and food shortage. These factors can induce stress responses in individuals (Creel et al., 2013). Thus, the density-induced stress responses are an additive stress effect of intrinsic and extrinsic factors, reflecting the biological cost of cumulative stress responses (Goymann \& Wingfield, 2004) rather than a single factor effect (i.e., antagonistic behaviour).

In the present study, we found that the influence of female- and male-founder vole numbers on the proportion of reproductive condition was mediated through FCM levels in 2012, and that female-founder number indirectly negatively affected recruitment through FCM levels in 2015. Although the influence of FCM levels on reproductive traits had different pathways in both years, we still conclude that density-induced stress participates in density-dependent reproduction; also, density-induced stress is one of the factors generating density-dependent reproduction effects.

In conclusion, in the present study, high density generated density-dependent reproduction and increased FCM levels of founders. The negative effect of high density on reproduction was partly through its positive effects on FCM levels of founder voles. Thus our results provide the first evidence that density-induced stress is one ecological factor generating density-dependent reproduction effects in vole populations.

Author contribution : Jianghui Bian and Yan Wu conceived and designed the experiments. Shouyang Du, Yanbin Yang and Yifan Cao performed the experiments. Jianghui Bian and Guozhen Shang analyzed the 
data. Guozhen Shang and Jianghui Bian wrote the manuscript. Yan Wu provided editorial advice.

Acknowledgements: We thank Hui He, Xuheng Nie, and Xin Zhang for their assistance in the field. This work was funded by the National Natural Science Foundation of China (Grant Numbers 31870397, and 31570421), the Natural Science Foundation of Qinghai Province (Grant Number 2018-ZJ-906), and the Strategic Priority Research Program of the Chinese Academy of Sciences (Grant/Award Number XDA2005010406). The use of animals in this study was in accordance with the guidelines of the regulations of experiments on animals and was approved by the Animal Ethics and Welfare Committee of the Northwest Institute of Plateau Biology, Chinese Academy of Science.

\section{Conflict of interest:}

The authors declare that they have no conflicts of interest.

\section{Data Accessibility Statement:}

Data in this manuscript are available on DRYAD (https://doi.org/10.5061/dryad.2280gb5sj).

\section{References}

Bian, J. H., Fan, N. C., Zeng, J. C., \& Shi, Y. Z. (1994). Studies on the successive relation between small mammal community and plant community in Alpine meadow. Acta Theriologica Sinica ,14 (03), 209-216 (in Chinese, English abstract). doi: 10.16829/j.slxb.1994.03.009.

Bian, J. H., Du, S. Y., Wu, Y., Cao, Y. F., Nie, X. H., He, H., \& You, Z. B. (2015). Maternal effects and population regulation: maternal density-induced reproduction suppression impairs offspring capacity in response to immediate environment in root voles Microtus oeconomus . Journal of Animal Ecology , 84 (2), 326-336. doi: org/10.1111/1365-2656.12307.

Boonstra, R., \& Boag, P. T. (1992). Spring declines in Microtus pennsylvanicus and the role of steroid hormones. Journal of Animal Ecology , 61 (2), 339-352. doi:10.2307/5326.

Boonstra, R. (2005). Equipped for life: the adaptive role of the stress axis in male mammals. Journal of Mammalogy , 86 (2), 236-247. doi: org/10.1644/BHE-001.1.

Charbonnel. N., Chaval, Y., Berthier, K., Deter, J., Morand, S., Palme, R., \& Cosson, J. F. (2008). Stress and demographic decline: a potential effect mediated by impairment of reproduction and immune function in cyclic vole populations. Physiological and Biochemical Zoology ,81 (1), 63-73. doi: 10.1086/523306.

Chen, F., Du, S. Y., Bian, J. H., You, Z. B., \& Wu, Y. (2012). Chronic hypoxia exposure during pregnancy is associated with a decreased active nursing activity in mother and an abnormal birth weight and postnatal growth in offspring of rats. Hormones and Behavior , 61 (4), 504-511. doi: org/10.1016/j.yhbeh.2012.01.009.

Christian, J. J. (1971). Population density and reproductive efficiency. Biology of Reproduction , 4 (3), 248-294. doi: org/10.1093/biolreprod/4.3.248.

Creel, S., Dantzer, B., Goymann, W., \& Rubenstein, D. R. (2013). The ecology of stress: effects of the social environment. Functional ecology , 27 (1), 66-80. doi: org/10.1111/j.1365-2435.2012.02029.x.

Edwards, P. D., \& Boonstra, R. (2018). Glucocorticoids and CBG during pregnancy in mammals: diversity, pattern, and function. General and comparative endocrinology , 259 , 122-130. doi: org/10.1016/j.ygcen.2017.11.012.

Edwards, P. D., Dean, E. K., Palme, R., \& Boonstra, R. (2019). Assessing space use in meadow voles: the relationship to reproduction and the stress axis. Journal of Mammalogy , 100 (1), 4-12. doi: org/10.1093/jmammal/gyy161.

Goymann, W., Wingfield, J. C. (2004). Allostatic load, social status and stress hormones: the costs of social status matter. Animal Behaviour , 67 (3), 591-602. doi: org/10.1016/j.anbehav.2003.08.007. 
Harper, J. M., \& Austad, S. N. (2004). Fecal corticosteroid levels in free-living populations of deer mice (Peromyscus maniculatus ) and southern red-backed voles (Clethrionomys gapperi). American midland naturalist , 152 (2), 400-410. doi: org/10.1674/0003-0031(2004)152[0400:FCLIFP]2.0.CO;2.

He, H., Cao, Y. F., Chen, L. L., Du, S. Y., Nie, X. H., \& Bian, J. H. (2013). The utility of detecting corticosterone levels in feces of root vole (Microtus oeconomus ). Acta Theirologica Sinica ,33 (2), 164-171 (in Chinese, English abstract) doi: 10.16829/j.slxb.2013.02.009.

Inchausti, P., Carslake, D., Attie, C., \& Bretagnolle, V. (2009). Is there direct and delayed density dependent variation in population structure in a temperate European cyclic vole population?. Oikos ,118 (8), 1201-1211. doi: $\operatorname{org} / 10.1111 / \mathrm{j} .1600-0706.2009 .17488 . x$.

Jiang, Y. J., Wei, S. W., Wang, Z. W., Zhen, Y. W., Cui, R. X., \& Sun, R. Y. (1991). Productivity investigation of the root vole (Microtus oeconomus) population in the Haibei alpine bushland (Potentilia fruticosa ) I. Population dynamics. Acta Theirologica Sinica, 11 (4), 270-278. (in Chinese, English abstract). doi: 10.16829/j.slxb.1991.04.006.

Koskela, E., Mappes, T., \& Ylonen, H. (1999). Experimental manipulation of breeding density and litter size: effects on reproductive success in the bank vole. Journal of Animal Ecology , 68 (3), 513-521. doi: org/10.1046/j.1365-2656.1999.00308.x.

Krebs, C. J., \& Myers, J. H. (1974). Population cycles in small mammals. Advances in ecological research, 8 , 267-399. doi: org/10.1016/S0065-2504(08)60280-9.

Krebs, C. J. (2002). Two complementary paradigms for analyzing population dynamics. Philosophical Transactions of the Royal Society of London, Series B, Biological Sciences , 357 (1425), 1211-1219. doi: org/10.1098/rstb.2002.1122.

Kuznetsov, V. A., Tchabovsky, A. V., Kolosova, I. E., \& Moshkin, M. P. (2004). Effect of habitat type and population density on the stress level of Midday Gerbils (Meriones meridianus ) in free-living population. Biology Bulletin of the Russian Academy of Sciences ,31 (6), 628-632. doi: org/10.1023/B:BIBU.0000049736.02912.e2.

Lee, A. K., \& McDonald, I. R. (1985). Stress and population regulation in small mammals. Oxford reviews of reproductive biology ,7 , 261-304.

Liu, J. K., Wang, X., \& Liu, W. (1991). Studies on the nutritional ecology of small herbivorous mammals: patterns of food selection and resource utilization for root voles and Gansu pikas. Alpine meadow Ecosystem, Fasc.3 (in Chinese) (eds J. Liu \& Z. Wang), pp. 111-124. Science Press, Beijing, China

Mcdonald, A. J. (1998). Cortical pathways to the mammalian amygdala.Progress in neurobiology , 55 (3), 257-332. doi: org/10.1016/S0301-0082(98)00003-3.

Novikov, E., \& Moshkin, M. (1998). Sexual maturation, adrenocortical function and population density of red-backed vole, Clethrionomys rutilus . Mammalia ,62 (4), 529-540 doi: 10.1515/mamm.1998.62.4.529.

Ostfeld, R. S., Canham, C. D., \& Pugh, S. R. (1993). Intrinsic density-dependent regulation of vole populations. Nature ,366 (6452), 259-261. doi: org/10.1038/366259a0.

Pihl, L., \& Hau, J. (2003). Faecal corticosterone and immunoglobulin A in young adult rats. Laboratory Animals , 37 (2), 166-171. doi: org/10.1258/00236770360563822.

Rodd, F. H., \& Boonstra, R. (1984). The spring decline in the meadow vole, Microtus pennsylvanicus : the effect of density. Canadian Journal of Zoology , 62(8), 1464-1473. doi: org/10.1139/z84-212.

Rodel, H. G., Bora, A., Kaiser, J., Kaetzke, P., Khaschei, M., \& Von Holst, D. (2004). Density-dependent reproduction in the European rabbit: a consequence of individual response and age-dependent reproductive performance. Oikos , 104 (3), 529-539. doi: org/10.1111/j.0030-1299.2004.12691.x. 
Saitoh, T. (1981). Control of female maturation in high density populations of the red-backed vole, Clethrionomys rufocanus bedfordiae. Journal of Animal Ecology, 50 (1), 79-87. doi:10.2307/4032.

Sapolsky, R. M. (2005). The influence of social hierarchy on Primate health. Science, 308 (5722), 648-652. doi: $10.1126 /$ science.1106477.

Saucy, F. (1994). Density Dependence in Time Series of the Fossorial Form of the Water Vole,Arvicola terrestris . Oikos , 71 (3), 381-392. doi: 10.2307/3545826.

Sheriff, M. J., Krebs, C. J., \& Boonstra, R. (2009). The sensitive hare: sublethal effects of predator stress on reproduction in snowshoe hares. Journal of Animal Ecology , 78 (6): 1249-1258. doi: org/10.1111/j.13652656.2009.01552.x.

Sheriff, M. J., Krebs, C. J., \& Boonstra, R. (2010). Assessing stress in animal populations: Do fecal and plasma glucocorticoids tell the same story?. General and comparative endocrinology, 166(3), 614-619. doi: org/10.1016/j.ygcen.2009.12.017.

Sun, R. Y., Zheng, S. W., \& Cui, R. X. (1982). Home range of the root vole Microtus oeconomus . Acta Theriologica Sinica ,2 (2), 219-231 (in Chinese, English abstract). doi: 10.16829/j.slxb.1982.02.014.

Sun, P., Zhao, X. Q., Xu, S. X., Zhao, T. B., \& Zhao, W. (2002). Changes after snow of the population characteristic of root vole (Microtus oeconomus ) in Haibei Alpine meadow. Acta Theriologica Sinica, 22 (04), 318-320 (in Chinese, English abstract) doi: 10.16829/j.slxb.2002.04.014.

Viblanc, V. A., Gineste, B., Stier, A., Robin, J. P., \& Groscolas, R. (2014). Stress hormones in relation to breeding status and territory lacation in colonial king penguin: a role for social density?. Oecologia , 175 (3), 763-772. doi: 10.1007/s00442-014-2942-6.

Wingfield, J. C., \& Sapolsky, R. M. (2003). Reproduction and resistance to stress: when and how. Journal of neuroendocrinology ,15 (8), 711-724. doi: org/10.1046/j.1365-2826.2003.01033.x.

Yang, Y. B., Shang, G. Z., Du, S. Y., Zhang, X., Wu, Y., \& Bian, J. H. (2018). Maternal density stress and coccidian parasitism: Synergistic effects on overwinter survival in root voles. Functional Ecology , 32 (9), 2181-2193. doi: org/10.1111/1365-2435.13129.

Zhang, Z. B., Xu, L., Guo, C., Wang, Y., \& Guo, Y. W. (2010). Effect of ENSO-driven precipitation on population irruptions of the Yangtze voleMicrotus fortis calamorum in the Dongting Lake region of China.Integrative Zoology , 5 (2), 176-184. doi: 10.1111/j.1749-4877.2010.00199.x.

\section{Figure legends}

Fig. 1 Population densities across live-trapping sessions in 2012 (A) and 2015 (C) and the numbers of founder individuals in 2012 (B) and 2015 (D). The population density was estimated as the minimum number known to be alive (MNKA) in each enclosure. Data from the four enclosures in each of the two density groups were expressed as mean +- standard error (SE).

Fig. 2 Mean (+- SE) recruitment in 2012 (A) and 2015 (B), mean the proportion of reproductive females in 2012 (C) and 2015 (D), and of reproductive males in 2012 (E) and 2015 (F), in the experimental periods. Data from the four enclosures in each of the two density groups were expressed as mean +- standard error (SE).

Fig. 3 The regression analysis of number of female founders with recruitment (A), the proportion of reproductive females (B) in 2012 and 2015, and the proportion of reproductive males (C) in 2015. Mean number of founders per enclosure was used as the independent variable and the corresponding recruitment and the proportion of reproductive condition per enclosure were the dependent variables. The female-founder number was negatively correlated with mean recruitment $\left(F_{1,6}=16.51, P=0.007\right.$ for $2012 ; F_{1,6}=15.93, P$ $=0.007$ for 2015$)$ and the proportion of reproductive females $\left(F_{1,6}=90.42, P<0.0001\right.$ for $2012 ; F_{1,6}$ 
$=6.34, P=0.045$ for 2015). The male-founder number was negatively correlated with the proportion of reproductive males in $2015\left(F_{1,6}=24.28, P=0.003\right)$, but not in $2012\left(F_{1,6}=2.93, P=0.138\right)$.

Fig. 4 Recursive models in structural equation model, testing the direct and indirect effects of founder number on and FCM level, recruitment and the proportion of reproductive condition. The structural equation model considered all plausible pathways in which trapping sessions and number and FCM levels influence reproduction. Arrows represent the flow of causality. Solid arrows represent a significant positive pathway; double-headed solid arrows, a significant negative pathway; dotted arrows, a non-significant pathway. Path coefficients associated with each arrow show standardised effect sizes. Numbers indicate the standard path coefficients. CT, cumulative time of trapping session; N, number of founders; P, proportion of reproductive condition; R, recruitment. ${ }^{*} P<0.05,{ }^{* *} P<0.001,{ }^{* * *} P<0.0001$. For the proportion of reproductive females, $\chi^{2}=4.00, P=0.26$, RMSEA $=0.07$ in 2012 and $\chi^{2}=2.00, P=0.91$, RMSEA $=0.00$ in 2015. For the proportion of males, $\chi^{2}=0.92, P=0.34$, RMSEA $=0.00$ in 2012 and $\chi^{2}=3.34, P=0.19$, RMSEA $=0.07$ in 2015. For recruitment, $\chi^{2}=3.27, P=0.35$, RMSEA $=0.04$ in 2012 and $\chi^{2}=2.17, P=0.34$, RMSEA $=0.04$ in 2015. RMSEA, root mean square error of approximation. 

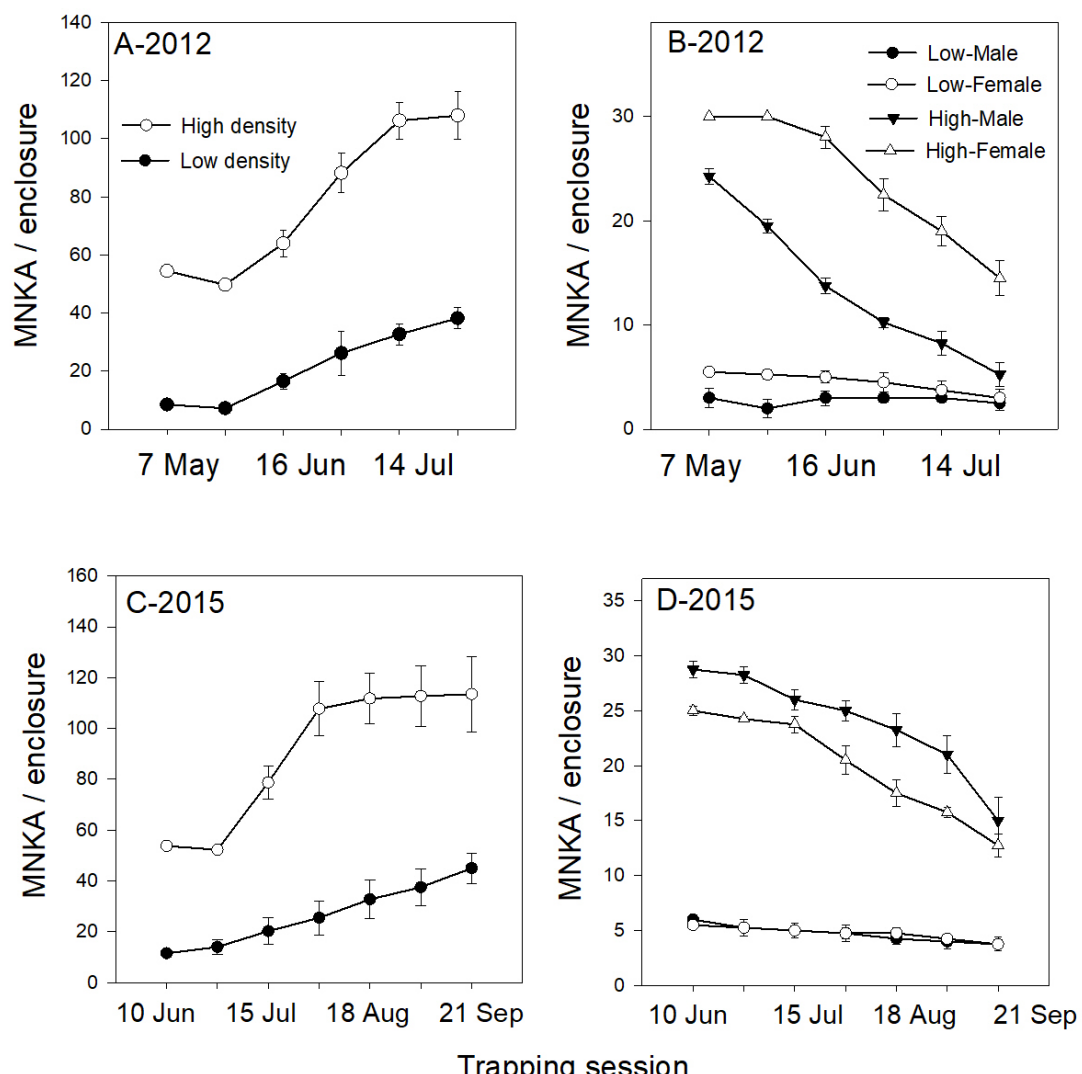

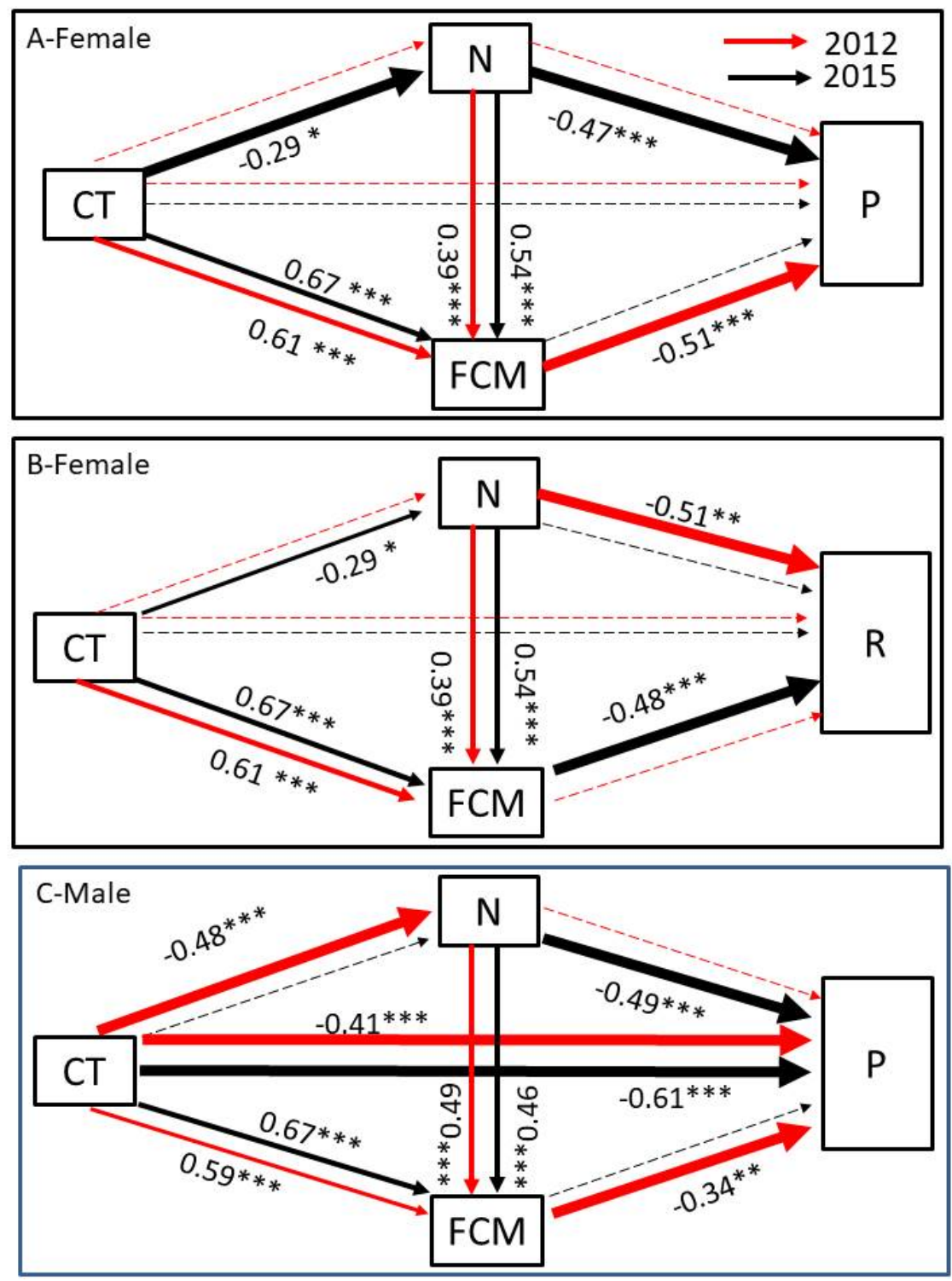

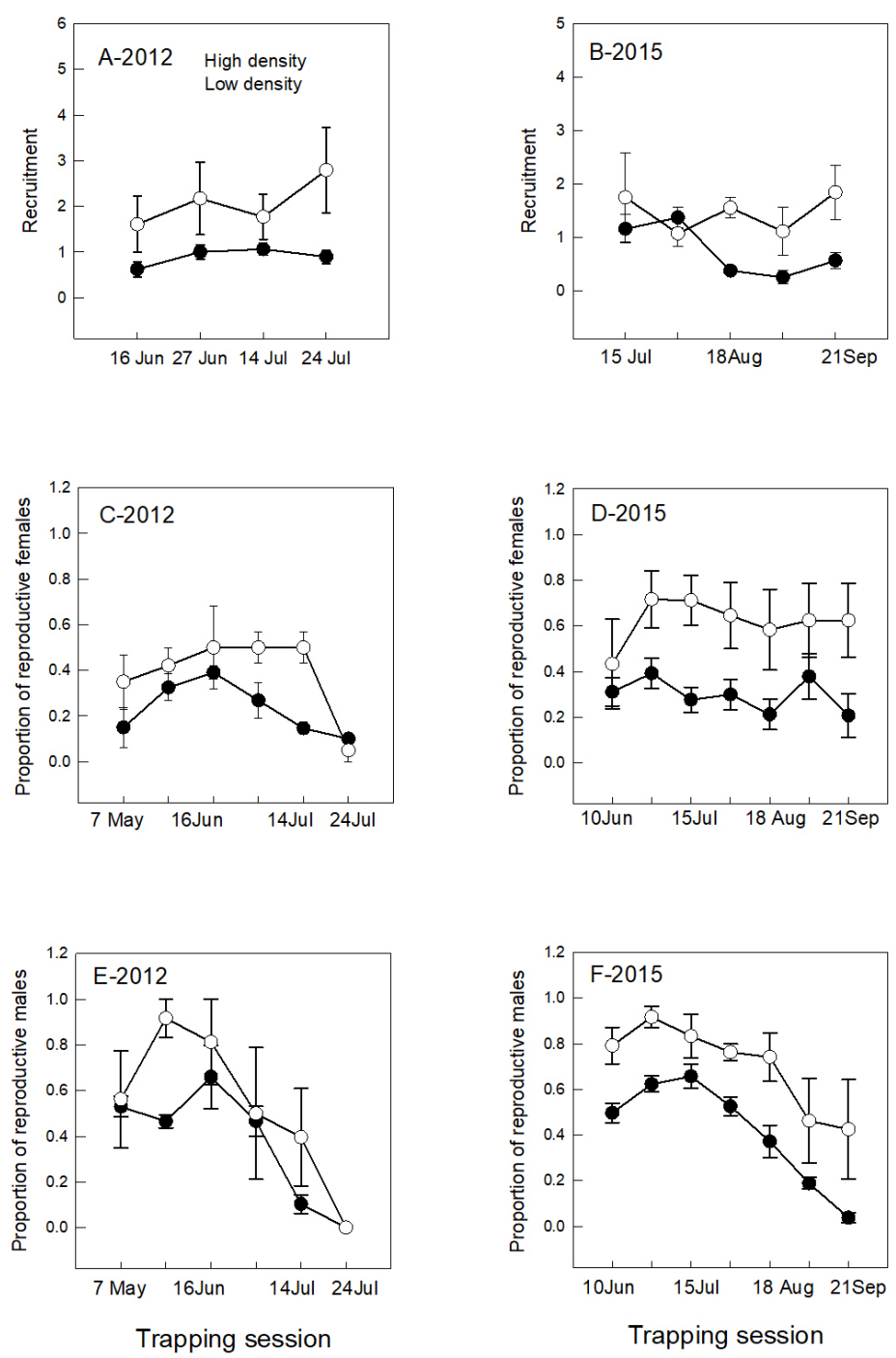

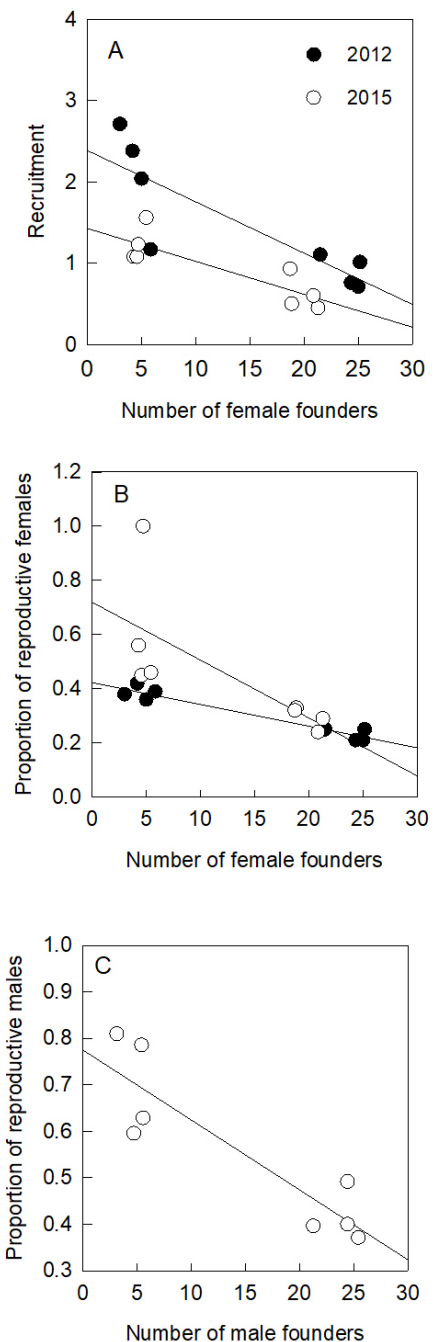